\title{
Long-term asthma treatment guided by airway hyperresponsiveness in children: a randomised controlled trial
}

\author{
M. Nuijsink*, W.C.J. Hop ${ }^{\#}$, P.J. Sterk ${ }^{\top}$, E.J. Duiverman ${ }^{+}$and J.C. de Jongste ${ }^{\S}$ \\ on behalf of the Children Asthma Therapy Optimal (CATO) Study Group ${ }^{f}$
}

ABSTRACT: Management plans for childhood asthma show limited success in optimising asthma control. The aim of the present study was to assess whether a treatment strategy guided by airway hyperresponsiveness (AHR) increased the number of symptom-free days and improved lung function in asthmatic children, compared with a symptom-driven reference strategy.

In a multicentre, double-blind, parallel-group, randomised, 2-yr intervention trial, 210 children (aged 6-16 yrs) with moderate atopic asthma, selected on the basis of symptom scores and/or the presence of AHR, were studied. At 3-monthly visits, symptom scores, forced expiratory volume in one second (FEV1) and methacholine challenge results were obtained, and medication (five levels of fluticasone with or without salmeterol) adjusted according to algorithms based on symptom score (reference strategy, $n=104$ ) or AHR and symptom score (AHR strategy, $n=102$ ).

After 2 yrs, no difference was found in the percentage of symptom-free days between treatment strategies. Pre-bronchodilator FEV1 was higher in the AHR strategy (2.3\% predicted). This was entirely explained by a gradual worsening of FEV 1 in a subgroup of 91 hyperresponsive children enrolled with low symptom scores (final difference between study arms was $6 \%$ ).

Asthma treatment guided by airway hyperresponsiveness showed no benefits in terms of number of symptom-free days, but produced a better outcome in terms of pre-bronchodilator forced expiratory volume in one second in allergic asthmatic children, especially those characterised by low symptom scores despite airway hyperresponsiveness.

KEYWORDS: Airway hyperresponsiveness, childhood asthma, inhaled corticosteroids, lung function in disease, salmeterol, symptom evaluation and management

$\mathbf{T}$ he long-term outcome of asthma depends upon the severity of the disease in early life; persistence into adulthood is more likely in children with more severe airway obstruction and airway hyperresponsiveness (AHR) [1]. It has recently been shown that childhood asthma is associated with reduced lung function in young adults [2]. Therefore, treatment strategies that preserve lung function in addition to controlling symptoms in childhood may offer substantial long-term benefits. Despite effective therapies, asthma control appears far from optimal in a large proportion of asthmatics worldwide [3]. One explanation is inadequate suppression of airway inflammation. Inhaled corticosteroids (ICS) are the first-choice antiinflammatory treatment for asthma, suppress airway inflammation and improve symptoms and lung function [4]. According to the Global Initiative for Asthma (GINA), ICS dosing is guided by symptoms and lung function [5]. However, the relationship between these parameters and severity of airway inflammation is weak or absent [6]. Moreover, several studies have shown persisting inflammation in the airways of well-controlled asthmatic patients despite treatment with ICS, and in patients showing clinical remission of asthma [7, 8]. These data indicate that not only symptoms or lung function but also inflammation should be considered when treating asthma with ICS. The validity of this concept is supported by a number of studies using different approaches.

In adult asthmatics, a treatment strategy focusing on the suppression of sputum eosinophilia resulted in a reduction in asthma exacerbations $[9,10]$. Sмітн et al. [11] found that titrating asthma therapy against exhaled nitric oxide fraction $(F \mathrm{eNO})$, an indirect marker of eosinophilic airway

\section{AFFILIATIONS}

*Dept of Paediatric Respiratory Medicine, Juliana Children's Hospital, The Hague,

\#Dept of Epidemiology and Biostatistics, Erasmus University Medical Centre, and

${ }^{\S}$ Dept of Paediatric Respiratory Medicine, Erasmus University Medical Centre/Sophia Children's Hospital, Rotterdam,

"Dept of Pulmonology, Academic Medical Centre, Amsterdam, and ${ }^{+}$Dept of Paediatric Respiratory Diseases, University Medical Centre Groningen, Groningen, The Netherlands.

${ }^{f}$ Members are listed in the Acknowledgements section.

CORRESPONDENCE

J.C. de Jongste, Dept of Paediatric Respiratory Medicine, Erasmus Medical Centre/Sophia Children's Hospital, P.0. Box 2060, 3000CB Rotterdam, The Netherlands. Fax: 31 104636811

E-mail: j.c.dejongste@ erasmusmc.nl

Received:

August 272006

Accepted after revision:

May 112007

SUPPORT STATEMENT

This study was initiated and designed by the Children Asthma Therapy Optimal (CATO) Study Group.

STATEMENT OF INTEREST

Statements of interest for all authors of this manuscript and for the study itself can be found at www.erj.ersjournal.com/misc/ statements/shtml

European Respiratory Journal Print ISSN 0903-1936 Online ISSN 1399-3003 
inflammation, resulted in a substantial reduction in ICS dose without compromising asthma control in adults. In a recent paediatric study, PIJNENBURG et al. [12] showed that a significant improvement in AHR could be reached by titrating ICS against FeNO, and this effect was obtained without increasing the mean ICS dose. AHR to inhaled methacholine is associated with airway inflammation and remodelling [7, 13]. SONT et al. [14] showed that ICS dose titration guided by AHR reduced the asthma exacerbation rate 1.8-fold, improved lung function and reduced remodelling in airway biopsy specimens from adult asthmatics. AHR is a risk factor for rapid decline in lung function [1], and severe AHR is associated with inadequate symptom perception $[15,16]$. Therefore, it could be reasoned that asthmatic children with AHR and inadequate symptom perception are especially at risk of a rapid decline in lung function and might, therefore, particularly benefit from titrating asthma therapy against AHR. The present study tested the hypothesis that a treatment strategy guided by AHR increases the number of asthma symptom-free days and provides better maintenance of lung function in children with moderately severe atopic asthma compared with a symptomdriven strategy.

\section{METHODS}

\section{Patients}

Clinically stable asthmatic children living in the Netherlands, aged 6-16 yrs and with a documented clinical history of moderate persistent asthma, according to GINA guidelines, were eligible and were enrolled from the 15 participating clinics, including seven university medical centres. All patients gave a positive, class $\geqslant 1$, radioallergosorbent test result for one or more airborne allergens and used $\geqslant 200 \mu \mathrm{g} \cdot \mathrm{day}^{-1}$ fluticasone or an equivalent dose of other ICS. The protocol allowed for inclusion of three different asthma phenotypes at randomisation were as follows. 1) Subgroup AHR ( $n=91$ $(44 \%))$ : children with a provocative dose of methacholine causing a $20 \%$ fall in forced expiratory volume in one second (FEV1; PD20) $<150 \mu \mathrm{g}$ and a cumulative symptom score $<14$. 2) Subgroup symptom $(S ; n=46(22 \%))$ : children with a symptom score $\geqslant 14$ and PD20 $\geqslant 150 \mu$ g. 3) Subgroup S+AHR $(n=69(34 \%))$ : children with a symptom score $>14$ and PD20 $<150 \mu \mathrm{g}$. By including these different phenotypes, the results were applicable to the disease spectrum in paediatric clinical practice. All parents and children aged $>12$ yrs signed their informed consent. The study was approved by the medical ethical committees of all the participating centres.

\section{Study design}

The present study was performed as a multicentre, parallelgroup, randomised, 2-yr intervention trial. Children were randomised after a run-in period of 1 month. In children treated with $500 \mu \mathrm{g} \cdot \mathrm{day}^{-1}$ fluticasone who did not meet the criteria for randomisation after 1 month, the dose of ICS was tapered down to $200 \mu \mathrm{g} \cdot \mathrm{day}^{-1}$ fluticasone for a further 2 months before randomisation. After run-in, children were randomised into one of two treatment strategy arms if they showed a cumulative symptom score $\geqslant 14$ during the last 2 weeks of the run-in period and/or a PD20 $<150 \mu \mathrm{g}$ (fig. 1). The subjects were allocated in consecutive order. Randomisation was performed centrally using a minimisation programme. Both treatment strategy groups were stratified for centre, baseline PD20 at the end of the run-in period (PD20 $\geqslant 150$ or $<150 \mu \mathrm{g}$ ), cumulative symptom score at the end of the run-in (symptom score $\geqslant 14$ or $<14$ ), starting dose of fluticasone (100 or $250 \mu \mathrm{g}$ b.i.d.) and age ( $<9$ or $\geqslant 9 \mathrm{yrs})$.

In the reference strategy arm, adjustment of treatment was based upon the cumulative symptom score alone. In the AHR strategy arm, treatment was adjusted on the basis of PD20 and symptom score, according to the algorithm shown in table 1 , with PD20 cut-off levels of 100 and $300 \mu \mathrm{g}$, corresponding to more severe and mild AHR, arbitrarily defined on the basis of current practice in the participating centres. During the run-in phase, patients were put on 100 or $250 \mu \mathrm{g}$ fluticasone b.i.d depending on their equivalent treatment before run-in. After randomisation, the children received treatment according to level 3 or 4 of the algorithm. Every 3 months, the cumulative symptom score, lung function (FEV1 and forced vital capacity (FVC)) and AHR were assessed by a lung function technician. Data were transmitted to a central computing facility that immediately produced dosing advice according to the study

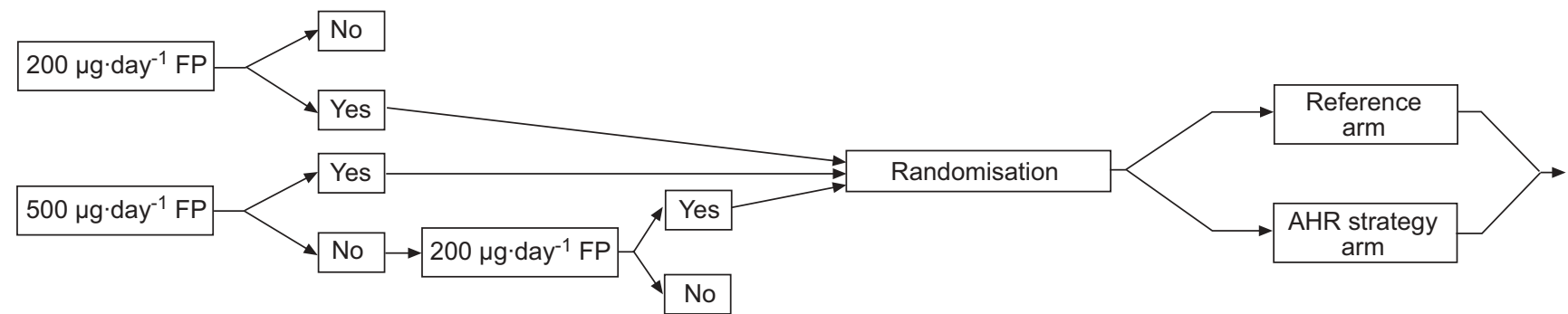

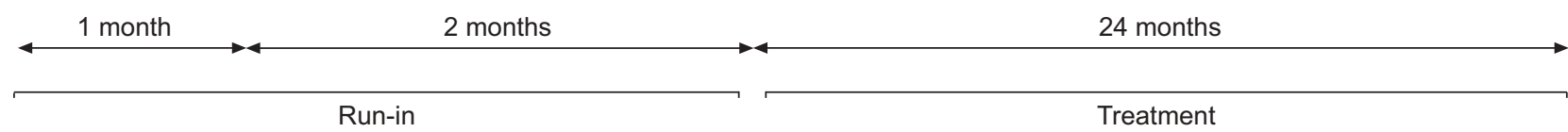

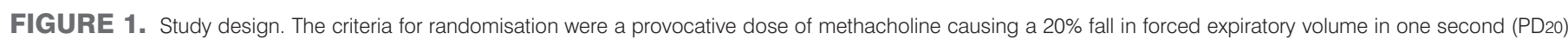

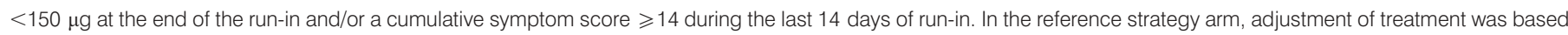

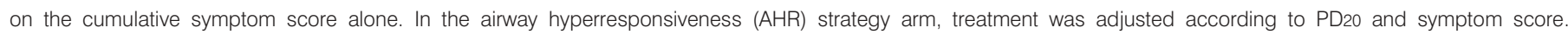
FP: fluticasone propionate. 'yes' and 'no' refer to either meeting the criteria for randomisation or not. 
TABLE 1 Study algorithm

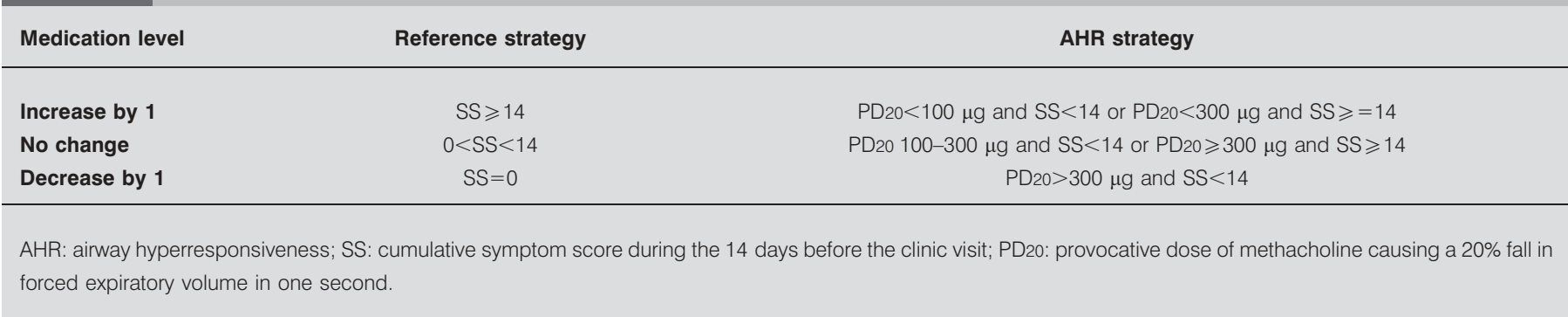

algorithm. This advice was communicated to the physician who was blinded to outcomes and study arm allocation.

During the treatment period, subjects used a fluticasone dry powder inhaler (Flixotide Diskus Brentford, UK), 100 or $200 \mu \mathrm{g} \cdot$ day $^{-1}$ (levels 1 and 2, respectively), or fluticasone/salmeterol multidose dry powder inhaler (Seretide Diskus ${ }^{\circledR}$; GlaxoSmithKline), 200/100, 500/ 100 or $1,000 / 100 \mu \mathrm{g} \cdot \mathrm{day}^{-1}$ (levels 3, 4 and 5, respectively; table 2). Medication levels were not blinded. For rapid relief of symptoms, $200 \mu \mathrm{g}$ salbutamol (Ventolin Diskus $\mathbb{R}$; GlaxoSmithKline) could be used. Subjects were asked to return all study medication at every visit and the remaining doses were counted. Compliance was defined as the number of doses used divided by the number of prescribed doses.

\section{Symptom scores}

During the study, patients filled in a diary card daily for 2 weeks before each visit, and for 3 months before the last visit [17]. Cough, shortness of breath and wheezing during night and day were recorded on a 4-point (0-3: no symptoms-severe symptoms interfering with activity or sleep) scale. The maximum 14-day cumulative score was 252. For each diary card period, the percentage of symptom-free days (defined as a score of 0 for cough, wheeze and shortness of breath) was determined.

\section{Lung function and $A H R$}

The study medication was stopped $36 \mathrm{~h}$ before lung function and AHR testing. During each visit, FEV1 and FVC were measured [18]. AHR was tested by methacholine challenge using a dosimeter method [19]. Nebulised methacholine bromide was given in doubling oral doses of $1.52-1,570 \mu \mathrm{g}$ via a DeVilbiss 646 nebuliser (DeVilbiss Health Care Inc., Somerset, PA, USA) attached to a Rosenthal-French or KoKo dosimeter (Laboratory for Applied Immunology, Fairfax, VA, USA). The PD20 was calculated from a log dose-response plot by linear interpolation of the data points. At the end of the challenge test, $400 \mu \mathrm{g}$ salbutamol was administered after a 20min pause and the FEV1 was measured again.

\section{Asthma exacerbations}

An exacerbation was defined as a deterioration of asthma requiring treatment with oral corticosteroids, as judged by the physician [20].

\section{Safety measures}

Standing height was measured every 3 months using a wallmounted Holtain stadiometer (Holtain, Crymych, UK). If a child showed a decrease in height of $0.125 \times$ SDS (standard deviation score) in 6 months on two subsequent visits, the data were reviewed by an a independent paediatric endocrinologist (W.J.M. Gerver, Dept of Paediatrics, Maastricht University Hospital, Maastricht, the Netherlands), and further evaluation could take place, including Tanner staging of puberty and radiological assessment of bone age. If serious growth problems were suspected, the patient could be withdrawn from the study.

\section{Statistical analysis}

Diary card data were aggregated per patient for each of the nine periods in the study (run-in and seven subsequent periods of 14 days each prior to the clinic visit, followed by a final period of 3 months at the end of the study). Changes in the mean percentage of symptom-free days were compared between treatment strategies using repeated measures ANOVA (rMANOVA; with unstructured covariance matrix), with adjustment for baseline percentage during run-in. In the various rMANOVA models, time of assessment was included as a discrete factor. The mean percentage of symptom-free days during the final 3 months was the primary end-point. Power calculation was based on data from a previous study [17]. With a two-sided $\alpha$ of $0.05,100$ patients were needed in each group in order to detect a $15 \%$ difference in symptom-free days at the end of the study with a power of $80 \%$. Lung function (FEV1 (\% predicted) and FEV1/FVC $\times 100(\%))$ was also analysed using rMANOVA, and the value measured at randomisation was used as a covariate. PD20 outcomes at the various visits were compared between study arms after logarithmic transformation. If, at a given visit, a patient did not reach the PD20 at the highest methacholine dose, this dose was considered a right-censored observation in the analysis. The risk of exacerbation was compared between treatment strategies using the log-rank test. Cumulative doses of ICS were compared between treatment strategies using the MannWhitney U-test. At baseline, a possibly relevant difference between the treatment strategies was found in the proportion of patients who had experienced exacerbations requiring

\section{TABLE 2 Study medication levels}

$\begin{array}{ll}\text { Level } 1 & 100 \mu \mathrm{g} \text { fluticasone o.d. } \\ \text { Level } 2 & 100 \mu \mathrm{g} \text { fluticasone b.i.d. } \\ \text { Level 3 } & 100 \mu \mathrm{g} \text { fluticasone } / 50 \mu \mathrm{g} \text { salmeterol b.i.d. } \\ \text { Level } 4 & 250 \mu \mathrm{g} \text { fluticasone } / 50 \mu \mathrm{g} \text { salmeterol b.i.d. } \\ \text { Level } 5 & 500 \mu \mathrm{g} \text { fluticasone } / 50 \mu \mathrm{g} \text { salmeterol b.i.d. }\end{array}$


prednisone treatment in the year before the study. Thus, all analyses were performed with an additional adjustment for this imbalance. Pre-planned subgroup analyses were performed for the three subgroups (AHR, $S$ and S+AHR). Adjusted differences of means between treatment strategies cited in the present study always refer to the outcome in the AHR strategy arm minus the outcome in the reference strategy arm. All analyses were performed according to the intentionto-treat principle. A p-value of 0.05 (two-sided) was considered the limit of significance.

\section{RESULTS}

Between December 1999 and November 2003, 288 children entered the run-in period, of whom 210 fulfilled the criteria for randomisation. As four patients withdrew within the first 3 months after randomisation and no follow-up data were available, 206 could be evaluated (fig. 2). The characteristics of the children in both treatment strategy arms and in the three subgroups are summarised in table 3 . At baseline, the patients in both arms were similar, except for a higher number of children in the AHR strategy arm who had experienced one or more asthma exacerbations in the year prior to the study.

\section{Symptom-free days}

The number of patients with an evaluable diary decreased from baseline to the end of the study from 104 to 90 for the reference strategy, and from 102 to 85 for the AHR strategy. Within each treatment strategy arm, the percentage of symptom-free days increased similarly. The mean \pm SEM percentage of symptom-free days within the reference and AHR strategy arms rose from $50 \pm 4$ to $71 \pm 3$ and from $47 \pm 3$ to $69 \pm 3$, respectively (both $\mathrm{p}<0.001$; fig. 3a). The adjusted difference in the mean percentage of symptom-free days between the strategy arms during the last 3 months was -1.1 (95\% confidence interval (CI) $-10.1-7.9 ; \mathrm{p}=0.84)$. Within the three subgroups, this difference was also nonsignificant $(3.1 \% \quad(p=0.63),-11.9 \% \quad(p=0.26)$ and $-3.2 \% \quad(p=0.72)$ for subgroups AHR, $\mathrm{S}$ and $\mathrm{S}+\mathrm{AHR}$, respectively; fig. $3 \mathrm{~b}-\mathrm{d})$.

\section{Lung function and AHR}

During the study, the number of patients with valid lung function results decreased from 101 to 92 in the reference strategy, and from 99 to 93 in the AHR strategy. Overall, the adjusted mean FEV1 (95\% CI) at the eight visits after randomisation was $2.3(0.05-4.6)$ percentage points higher in the AHR strategy arm ( $\mathrm{p}=0.046$; fig. 4a). Children with AHR and well-controlled symptoms at randomisation (subgroup AHR) exhibited a significantly higher FEV1 in the AHR strategy arm than in the reference strategy arm $(p=0.024)$. The adjusted difference in FEV1 between the two treatment strategies in the AHR subgroup after 2 yrs of treatment was 6.0 $(1.2-10.8) \%$ pred in favour of the AHR strategy arm $(p=0.017$; fig. $4 \mathrm{~b}$ ). This difference was explained by a gradual decrease in the reference strategy arm from $97 \pm 2 \%$ pred at randomisation to $93 \pm 2 \%$ pred after 2 yrs $(\mathrm{p}=0.027)$, whereas FEV1 did not change within the AHR strategy arm $(97 \pm 2$ to $98 \pm 2 \%$ pred; $p=0.23)$. In subgroups $S$ and $S+A H R$, there were no significant changes in FEV1 between treatment strategies after 2 yrs $(-2.0$ $(p=0.55)$ and $-0.15 \%$ pred $(p=0.98)$, respectively). Of the two results, the first was borderline significantly different $(\mathrm{p}=0.052)$ from the corresponding difference of $6.0 \%$ pred in the AHR subgroup. In the AHR subgroup, the mean FEV1/ FVC at the end of the study was $1.6(0.3-2.9)$ percentage points higher in the AHR strategy arm $(p=0.015)$. In the other two subgroups (S and S+AHR), differences were nonsignificant (both $\mathrm{p}>0.17$ ). The PD20 increased significantly during the treatment period. No difference was found between reference and AHR strategies (the change from baseline at 2 yrs was 2.6 and 2.8 doubling doses, respectively).

\section{Treatment strategies and ICS dose}

In the AHR strategy arm, $47 \%$ of decisions would have been different had patients been treated according to the reference strategy; it would have led to a higher medication level in $24 \%$ and to a lower level in $23 \%$. The mean \pm SEM daily ICS dose was $478 \pm 27 \mu \mathrm{g}$ fluticasone in the reference strategy arm and $562 \pm 26 \mu \mathrm{g}$ in the AHR arm $(\mathrm{p}=0.025)$. However, at the end of the study, the difference between the treatment strategy arms was nonsignificant $\left(505 \mu \mathrm{g} \cdot \mathrm{day}^{-1}\right.$ in reference strategy and $557 \mu \mathrm{g} \cdot \mathrm{day}^{-1}$ in AHR strategy; $\mathrm{p}=0.428$; fig. $5 \mathrm{a}$ ). The largest difference between strategies was seen after 6 months in the AHR subgroup (fig. 5b). The mean \pm SD compliance with treatment was excellent, $89 \pm 9 \%$ in the reference strategy arm and $88 \pm 8 \%$ in the AHR strategy arm. Compliance was equally good in children with and without symptoms (subgroups $S$ and S+AHR versus subgroup AHR).

\section{Asthma exacerbations}

During the study, 17 out of 104 subjects in the reference strategy arm experienced at least one asthma exacerbation, versus 16 out of 102 in the AHR strategy arm $(p=0.69)$. During the year before the study, these figures were 12 and 25, respectively.

\section{Side-effects}

At the end of the study, no significant difference in change in growth rate was found between the treatment strategies (baseline adjusted difference of $-0.1 \times$ SDS (95\% CI $-0.2-0.04$ ); $\mathrm{p}=0.18)$. However, in the AHR subgroup, a significant height difference was found between the treatment strategies at the end of the study (adjusted difference of $-0.4 \times \operatorname{SDS}(95 \% \mathrm{CI}$ $-0.6-0.2) ; \mathrm{p}<0.001)$. Growth data were not a reason for discontinuing the study in any subject.

\section{DISCUSSION}

It has been shown that, in allergic asthmatic children, 2 yrs of AHR-driven treatment did not improve the percentage of symptom-free days, but resulted in better pre-bronchodilator FEV1, especially in a large subgroup whose asthma was characterised by AHR and low symptom scores. Adjusting maintenance treatment solely based on symptoms in this subgroup produced a gradual deterioration in pre-bronchodilator FEV1 during the treatment period of 2 yrs.

Inflammation is associated with structural changes in the airways, and one of the major functional consequences of airway inflammation and remodelling is considered to be AHR [13]. Remodelling has been found in early stages of childhood asthma, and it is not known whether remodelling is responsible for long-term changes in lung function in childhood asthma [21]. However, prolonged ICS treatment results in progressive improvement in AHR [22]. This might be an important therapeutic objective, since AHR correlates with the 


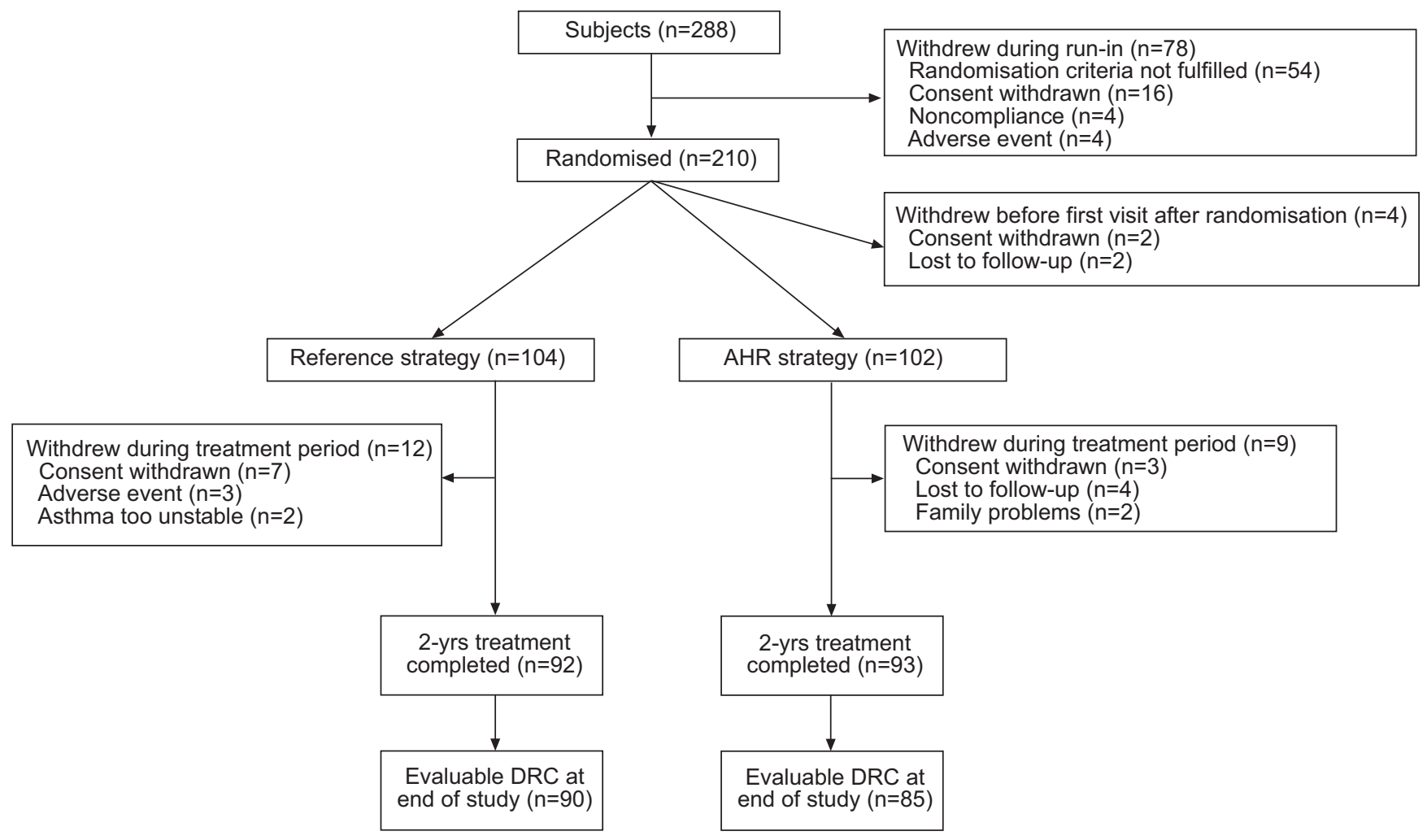

FIGURE 2. Trial profile. AHR: airway hyperresponsiveness; DRC: daily record card.

long-term prognosis of lung function development and with the risk of persistence of disease into adulthood [23-25]. Indeed, young adult asthmatics already show loss of lung function in comparison with controls [2]. Late introduction of ICS or inadequate dosing may well promote such lung function impairment [23].
Several studies have examined the long-term effects of ICS in children with asthma. The Childhood Asthma Management Program (CAMP) study [26] found that ICS improved pre- but not post-bronchodilator FEV1 compared with placebo, suggesting an effect of treatment on smooth muscle tone, rather than airway structure, and no loss of lung function.

\section{TABLE 3 Anthropometric data of subjects in two treatment strategies and three subgroups}

\begin{tabular}{|c|c|c|c|c|c|}
\hline & \multicolumn{2}{|c|}{ Strategy } & \multicolumn{3}{|c|}{ Subgroup } \\
\hline & Reference & AHR & $\mathrm{AHR}^{\#}$ & $\mathbf{s}^{*}$ & $\mathbf{S}+\mathbf{A H R}^{+}$ \\
\hline Subjects $n$ & 104 & 102 & 91 & 46 & 69 \\
\hline Males/females $\mathbf{n}$ & $54 / 50$ & $63 / 39$ & $54 / 37$ & $30 / 16$ & $33 / 36$ \\
\hline Age yrs & $10.9 \pm 2.5$ & $10.8 \pm 2.4$ & $10.7 \pm 2.5$ & $11.0 \pm 2.1$ & $11.0 \pm 2.5$ \\
\hline Duration of asthma yrs & $7.1 \pm 3.0$ & $7.3 \pm 3.1$ & $7.3 \pm 3.0$ & $7.0 \pm 3.3$ & $7.3 \pm 3.0$ \\
\hline Duration of ICS usage yrs & $5.2 \pm 2.7$ & $5.8 \pm 2.7$ & $5.4 \pm 2.9$ & $5.4 \pm 3.0$ & $5.7 \pm 2.4$ \\
\hline Asthma exacerbations in year prior to study $n$ & 12 & 25 & 20 & 5 & 12 \\
\hline FEV $_{1} \%$ pred & $98 \pm 14$ & $96 \pm 14$ & $97 \pm 15$ & $100 \pm 12$ & $94 \pm 14$ \\
\hline $\mathrm{FEV}_{1} / \mathrm{FVC} \%$ & $83 \pm 8$ & $81 \pm 9$ & $81 \pm 9$ & $86 \pm 6$ & $81 \pm 8$ \\
\hline PEF variability $\%$ & $7 \pm 4$ & $7 \pm 4$ & $6 \pm 3$ & $7 \pm 5$ & $8 \pm 5$ \\
\hline $\mathrm{PD}_{20} \mu \mathrm{g}$ & $73(0.8->1570)$ & $68(0.8->1570)$ & $47(3-148)$ & $553(154->1570)$ & $42(0.8-144)$ \\
\hline Run-in SS & $17(0-87)$ & $17(0-152)$ & $2(0-13)$ & $28(14-100)$ & $31(15-152)$ \\
\hline
\end{tabular}

Data are presented as mean \pm SD or median (range), unless otherwise stated. AHR: airway hyperresponsiveness; S: symptom; ICS: inhaled corticosteroid; FEV1: forced expiratory volume in one second; \% pred: \% predicted; FVC: forced vital capacity; PEF: peak expiratory flow; PD20: provocative dose of methacholine causing a 20\% fall in FEV1; SS: cumulative symptom score during the last 14 days before the clinic visit. ${ }^{\#}$ : well-controlled symptoms and AHR during run-in; ${ }^{\bullet}$ : manifest symptoms without AHR during run-in; ${ }^{+}$: manifest symptoms and AHR during run-in. 


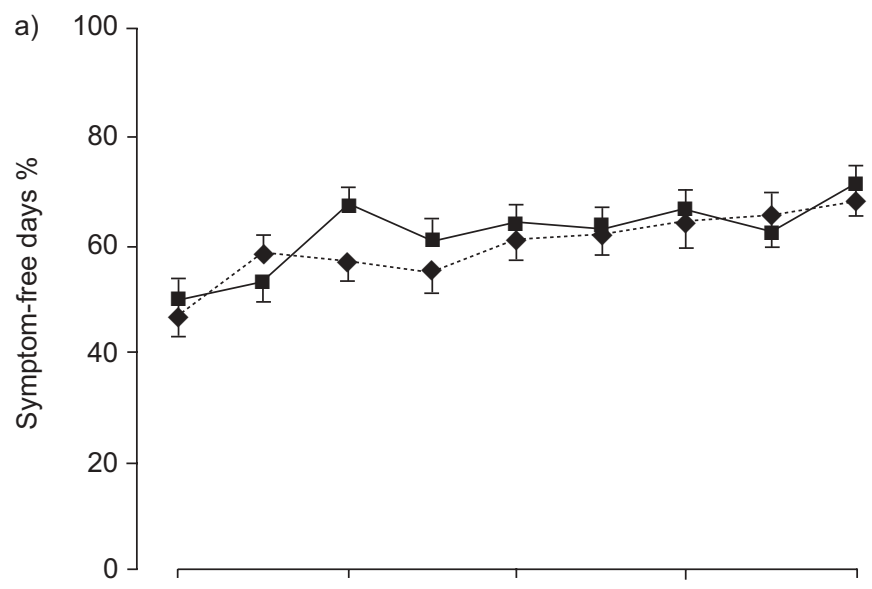

b)
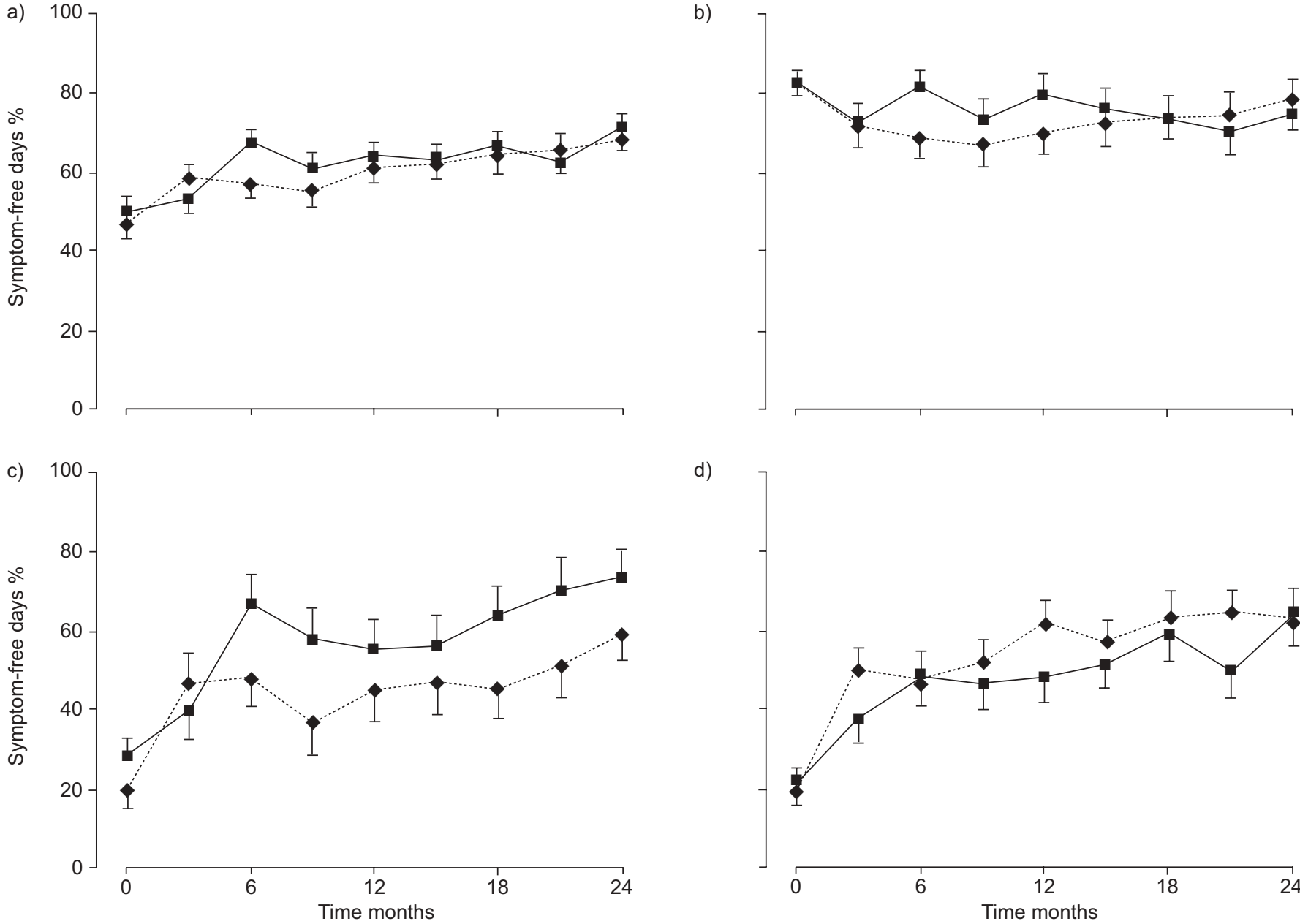

d)

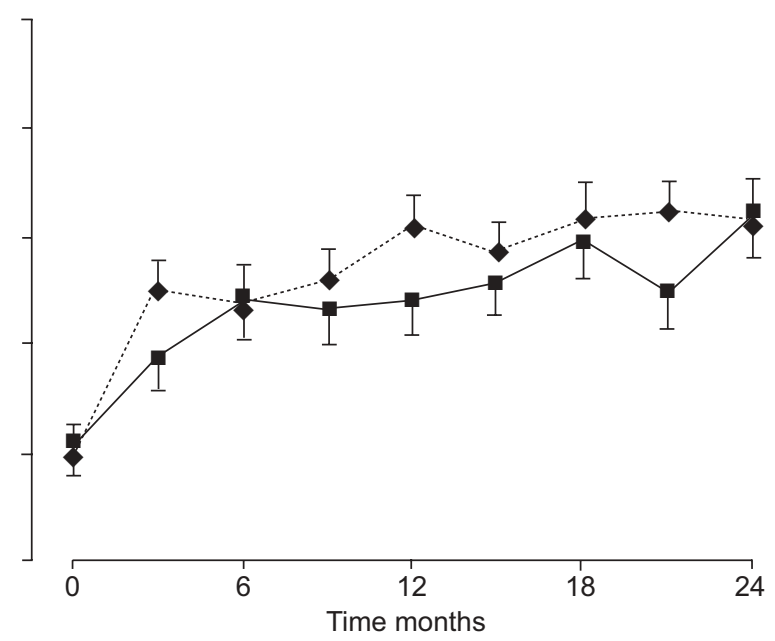

FIGURE 3. Symptom-free days as a function of time during follow-up

reference strategy:

: airway hyperresponsiveness (AHR) strategy) in: a) total study population ( $n=206$ ); b) AHR subgroup (AHR and well-controlled symptoms during run-in; $n=91$ ); c) symptom (S) subgroup (manifest symptoms without AHR during run in; $\mathrm{n}=46$ ); and d) S+AHR subgroup (manifest symptoms and AHR during run in; $\mathrm{n}=69$ ). Error bars represent SEM at each visit. The adjusted difference in the mean percentage of symptom-free days during the last 3 months did not differ between the strategy arms.

The pre-bronchodilator FEV1/FVC ratio was also significantly higher in steroid-treated children compared with the placebo group, consistent with less airway obstruction. Indeed, the large inhaled Steroid Treatment As Regular Therapy (START) in early asthma study [27] showed a small increase in prebronchodilator FEV1 as a result of steroid treatment when comparing ICS and placebo. Both studies were essentially different from the present one, in which the focus was not on ICS versus placebo but on treatment strategies. In addition, the participating children were already being treated with ICS in specialist practices prior to the study, and used higher inhaled steroid doses than in the CAMP or START studies. It is remarkable that there was no reduction in FEV1 with placebo treatment in both studies; indeed, a small increase was observed. The present authors speculate that this may be related to initial asthma severity. MERKUS et al. [28] examined the effect of ICS on the progression of FEV1 in children aged $>3$ yrs, and showed preservation of lung function compared with placebo. In children receiving placebo, pre- and postbronchodilator values ran largely in parallel, whereas a ceiling effect towards a submaximal level was seen with ICS.
How can the beneficial effect on lung function of treatment guided by AHR be explained? Conflicting data on the effects of medium- and long-term treatment with ICS on airway remodelling have been published $[14,29,30]$. AHR is a risk factor for a rapid decline in lung function in asthma, and, moreover, the decline in lung function with age in asthmatics correlates with the severity of AHR [1, 22, 31]. Several studies have shown that AHR is inversely associated with growth of airway calibre [32]; therefore, it is possible that airway growth benefits from the AHR strategy. The present authors speculate that the gradual and consistent effects on FEV1 of the AHR strategy represent a preventive and, perhaps, therapeutic effect of ICS on airway remodelling.

Using both treatment strategies, the percentage of symptomfree days increased. Possible reasons include an effect of medication, increased compliance with treatment or spontaneous improvement of disease. An effect of treatment seems plausible and could be caused by ICS or long-acting $\beta_{2}$ agonists (LABAs). Most of the time, LABAs were used by most children according to GINA guidelines and could have 

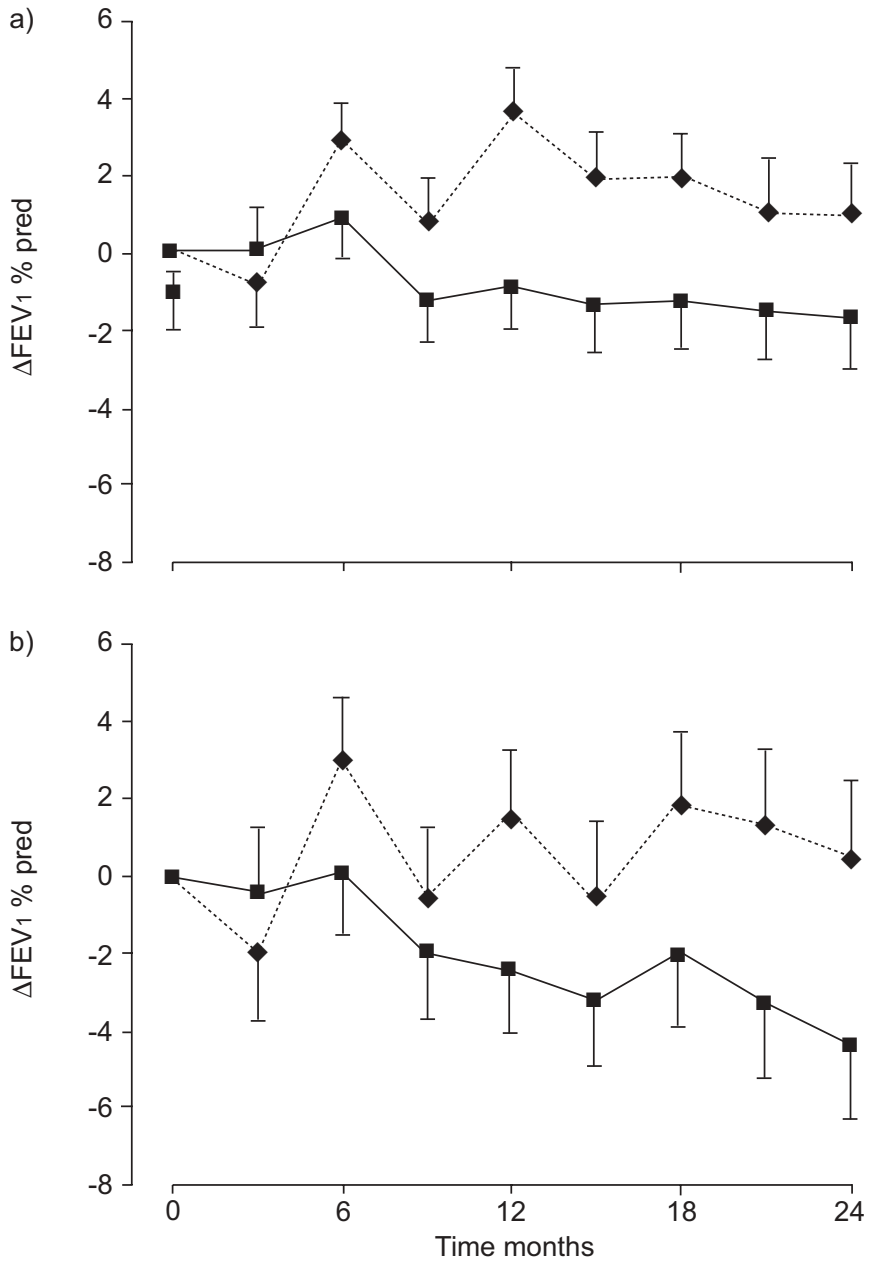

FIGURE 4. Change $(\Delta)$ from baseline in forced expiratory volume in one second (FEV1) as a function of time during follow-up ( $\mathbf{\square}$ : reference strategy; airway hyperresponsiveness (AHR) strategy) in: a) total study population $(n=206)$ and b) AHR subgroup (AHR and well-controlled symptoms during run-in; $n=91$ ). Error bars represent SEM. During the treatment period, the mean difference in change from baseline FEV 1 was $2.3 \%$ pred in the total study population $(p=0.046)$. After 2 yrs of treatment, the adjusted difference in change from baseline of FEV between the two treatment strategies was $6.0 \%$ pred in the AHR subgroup $(p=0.017)$

reduced symptoms. At baseline, symptom scores were unaffected by LABAs as these were not allowed during runin. The study design did not allow for disentangling the effects of ICS and LABAs.

AHR was defined on the basis of fixed cut-off levels, and it may be argued that this is inappropriate for children of a wide age range. LESOUËF [33] reasoned that, merely as a result of different lung size, the same dose of methacholine would have a stronger effect in smaller children. In the absence of agespecific data for determining AHR, there is currently no means of solving this problem. The impact on the present study may be limited, as the treatment arms were stratified for age. However, it is probable that selection on the basis of a fixed level of AHR has favoured the inclusion of young patients with less severe AHR.
Of the present study population, $44 \%$ initially showed low symptom scores despite AHR, suggesting that this phenotype is common in the present secondary and tertiary care setting. Pre-planned analysis of this subgroup revealed that the AHR, but not the reference, strategy prevented worsening of prebronchodilator FEV1 over 2 yrs of follow-up. In the remaining children, asthma outcome could not be improved by taking AHR into account. The present treatment algorithms predictably resulted in an increase in ICS dose in children with wellcontrolled symptoms treated according to the AHR strategy. A transient difference in ICS dose between the treatment strategies was seen over the course of the 2 yrs of treatment. This indicates that the AHR strategy was able to selectively improve the targeting of ICS to children in whom the reference strategy seems suboptimal. Overall, the increase in ICS dose was entirely explained by dose changes during the first two visits following randomisation. The cut-off symptom score at which the level of medication had to be increased was determined on the basis of a previous study using the same diary card [17]. The median symptom score at the start of the present study was higher than the pre-defined cut-off level, suggesting more severe disease in the present study than in the previous one. Studies published recently show that the doseresponse relationship of inhaled fluticasone with symptoms and FEV1 reaches a plateau at 200-400 $\mu \mathrm{g} \cdot$ day $^{-1}$ [34]. Based on these data, the present highest level of study medication could be questioned. However, not only dose but also inhaler technique and means of delivery of ICS determine their efficacy, and data from adults may not apply to children. More recently, systemic side-effects of fluticasone have been reported at doses of $\geqslant 500 \mu \mathrm{g} \cdot \mathrm{day}^{-1}$ [35]. At the onset of the present study, fluticasone doses of $\leqslant 1,000 \mu \mathrm{g} \cdot$ day $^{-1}$ were common practice in the participating clinics, and it was felt appropriate to continue this practice during the study. Whether similar long-term benefit could be derived from lower doses of ICS in children warrants further study.

In the present study, children were treated in line with GINA guidelines, often combining LABAs and an ICS. As LABAs improve symptoms but not inflammation, it could be argued that this affected assignment to subgroups and symptom scores. However, baseline symptom scores were obtained during the run-in period, when LABAs were not allowed. Furthermore, all lung function tests were performed $\geqslant 36 \mathrm{~h}$ after the last dose of study medication and, therefore, not influenced by LABAs. Finally, the cumulative proportion of children treated with LABAs did not differ between treatment strategies, and it seems likely that any effect of LABAs on symptoms will have been similar in both study arms. Consequently, the present authors are confident that the use of LABAs has not systematically biased the results of the present comparisons.

No adverse effects of ICS treatment on statural growth was found in the group as a whole, but a slight-but-significant reduction in growth velocity was observed in the AHR subgroup who were treated with relatively high ICS doses. Previous studies designed to evaluate growth in asthmatic children have shown that growth rates are commonly reduced during the first months of ICS treatment, but that this does not affect adult height [36]; thus, a negative effect on adult height is unlikely. 

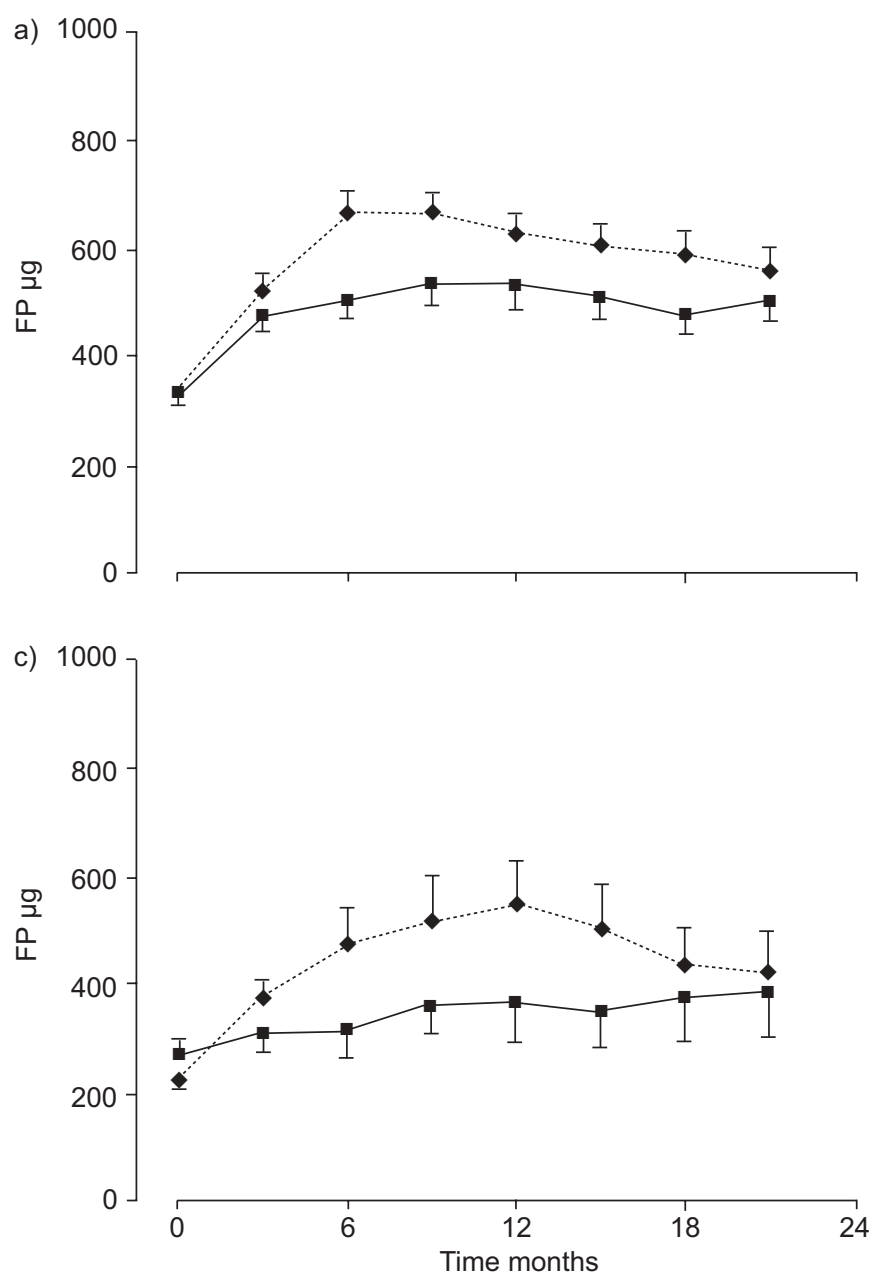

b)

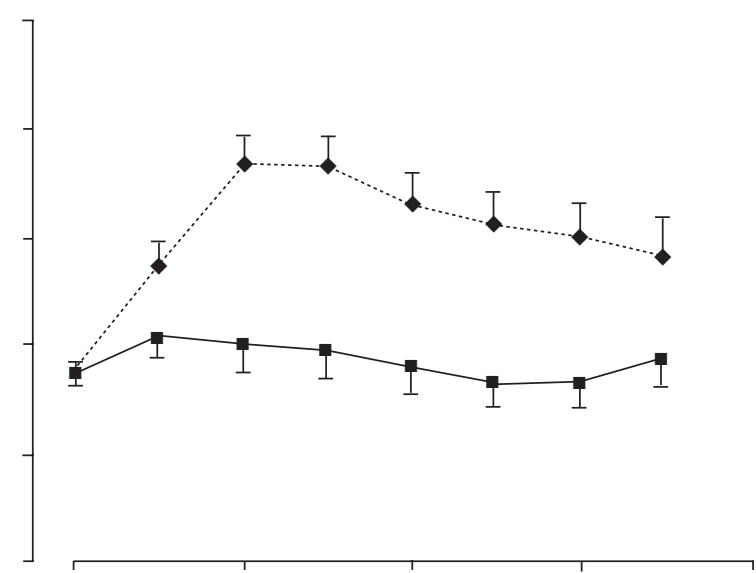

d)

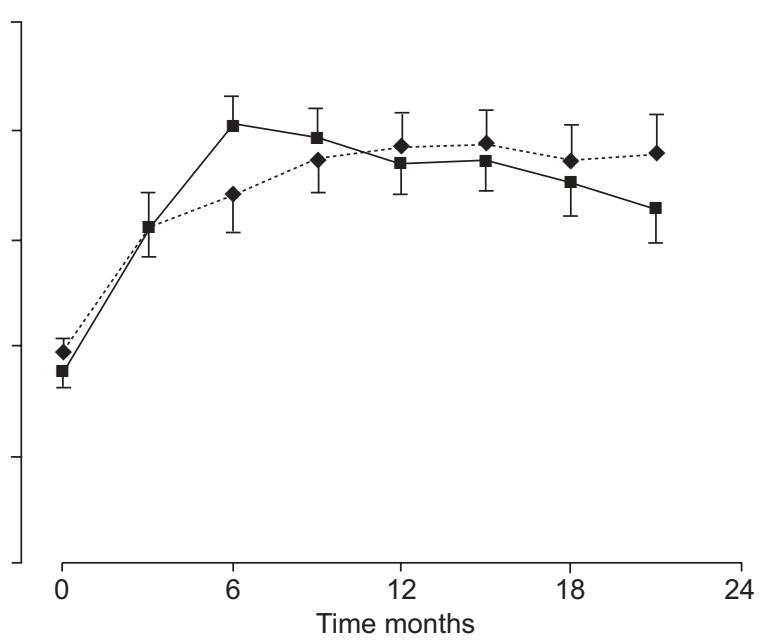

FIGURE 5. Daily fluticasone propionate (FP) dose during follow-up

: reference strategy;

: airway hyperresponsiveness (AHR) strategy) in: a) total study population

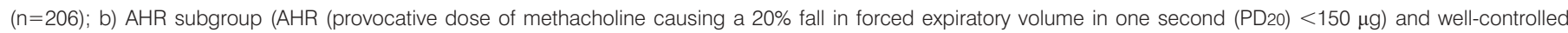

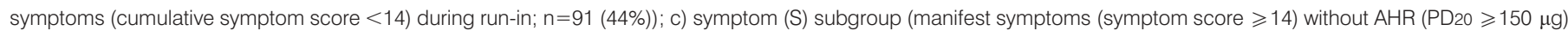

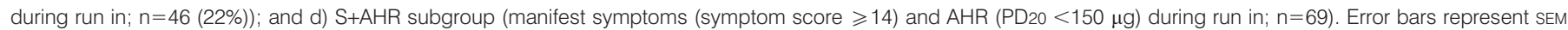

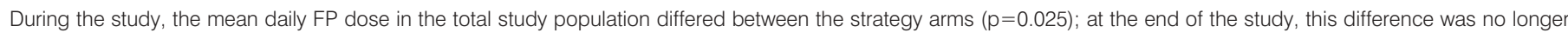
significant $(p=0.428)$. During and at the end of the study, the mean daily FP dose in the AHR subgroup differed between the strategy arms $(p<0.001)$.

What are the clinical implications of the present study? Asthmatic children characterised by AHR and well-controlled symptoms are obviously at risk of suboptimal treatment when treated according to the severity of their symptoms. However, measurement of AHR is currently rare in paediatric practice and is time consuming. The present authors would not advocate routine AHR measurements in all asthmatic children for that reason. However, AHR testing may be worthwhile in asthmatic children who report few symptoms in order to identify those at risk of lung function deterioration.

In conclusion, it was found that an airway hyperresponsivenessdriven asthma treatment, as compared with the conventional symptom-driven strategy, produced no improvement in the percentage of symptom-free days, but prevented long-term worsening of pre-bronchodilator forced expiratory volume in one second, specifically in a large subgroup of children who show airway hyperresponsiveness and low symptom scores.
This effect on lung function was achieved with higher doses of inhaled corticosteroids. The present authors speculate that phenotype-specific treatment strategies have the potential to improve the outcome of childhood asthma into adult life.

\section{ACKNOWLEDGEMENTS}

The members of the Children Asthma Therapy Optimal (CATO) Study Group (all from the Netherlands) are as follows. M. Nuijsink, J.M. Kouwenberg, A.J. Sprij (Dept of Paediatric Respiratory Medicine, Juliana Children's Hospital, The Hague); W.C.J. Hop (Dept of Epidemiology and Biostatistics, Erasmus University Medical Centre, Rotterdam); J.C. de Jongste (Dept of Paediatric Respiratory Medicine, Erasmus University Medical Centre/Sophia Children's Hospital, Rotterdam); J.M. Boogaard (Dept of Pulmonology, Erasmus University Medical Centre, Rotterdam); P.J. Sterk, E.R.V.M. Rikkers-Mutsaerts (Leiden University Medical Centre, Leiden); 
E.J. Duiverman (Dept of Paediatric Respiratory Diseases, University Medical Centre Groningen, Groningen University, Groningen); O.H. van der Baan-Slootweg, E.E.M. van Essen-Zandvliet (Heideheuvel Asthma Centre, Hilversum); N.J. van den Berg (Flevo Hospital, Almere); P.L.P. Brand, R.J. Roorda, A.W.A. Kamps (Isala Klinieken, Zwolle); G. Brinkhorst (Medical Centre, Alkmaar); J.E Dankert-Roelse, A.F. Nagelkerke (Free University Medical Centre, Amsterdam); J.C. van Nierop (Academic Medical Centre, Amsterdam); R. van Gent (Maxima Medical Centre, Veldhoven); J.W.C.M. Heijnens (Maasland Hospital, Sittard); J.J.E. Hendriks, Q. Jöbsis (Maastricht University Hospital, Maastricht); J. van der Laag, H.J.L. Brackel (University Medical Centre/Wilhelmina Children's Hospital, Utrecht); and A.A.P.H. Vaessen-Verberne (Amphia Hospital, Breda).

\section{REFERENCES}

1 Grol MH, Gerritsen J, Vonk JM, et al. Risk factors for growth and decline of lung function in asthmatic individuals up to age 42 years. A 30-year follow-up study. Am J Respir Crit Care Med 1999; 160: 1830-1837.

2 James AL, Palmer LJ, Kicic E, et al. Decline in lung function in the Busselton Health Study: the effects of asthma and cigarette smoking. Am J Respir Crit Care Med 2005; 171: 109-114.

3 Rabe KF, Adachi M, Lai CK, et al. Worldwide severity and control of asthma in children and adults: the global asthma insights and reality surveys. J Allergy Clin Immunol 2004; 114: 40-47.

4 Barnes PJ, Pedersen S, Busse WW. Efficacy and safety of inhaled corticosteroids. New developments. Am J Respir Crit Care Med 1998; 157: Suppl. 1, S1-S53.

5 National Institutes of Health, National Heart, Lung, and Blood Institute. Global Initiative for Asthma. Global Strategy for Asthma Management and Prevention. Bethesda, National Institutes of Health, 2004. Publication No. 02-3659.

6 Djukanović R, Wilson JW, Britten KM, et al. Effect of an inhaled corticosteroid on airway inflammation and symptoms in asthma. Am Rev Respir Dis 1992; 145: 669-674.

7 Sont JK, Han J, van Krieken JM, et al. Relationship between the inflammatory infiltrate in bronchial biopsy specimens and clinical severity of asthma in patients treated with inhaled steroids. Thorax 1996; 51: 496-502.

8 van den Toorn LM, Overbeek SE, de Jongste JC, Leman K, Hoogsteden HC, Prins JB. Airway inflammation is present during clinical remission of atopic asthma. Am J Respir Crit Care Med 2001; 164: 2107-2113.

9 Green RH, Brightling CE, McKenna S, et al. Asthma exacerbations and sputum eosinophil counts: a randomised controlled trial. Lancet 2002; 360: 1715-1721.

10 Jayaram L, Pizzichini MM, Cook RJ, et al. Determining asthma treatment by monitoring sputum cell counts: effect on exacerbations. Eur Respir J 2006; 27: 483-494.

11 Smith AD, Cowan JO, Brassett KP, Herbison GP, Taylor DR. Use of exhaled nitric oxide measurements to guide treatment in chronic asthma. N Engl J Med 2005; 352: 2163-2173.

12 Pijnenburg MW, Bakker EM, Hop WC, de Jongste JC. Titrating steroids on exhaled nitric oxide in children with asthma: a randomized controlled trial. Am J Respir Crit Care Med 2005; 172: 831-836.

13 Boulet LP, Chakir J, Dubé J, Laprise C, Boutet M, Laviolette M. Airway inflammation and structural changes in airway hyper-responsiveness and asthma: an overview. Can Respir J 1998; 5: 16-21.

14 Sont JK, Willems LN, Bel EH, van Krieken JH, Vandenbroucke JP, Sterk PJ. Clinical control and histopathologic outcome of asthma when using airway hyperresponsiveness as an additional guide to long-term treatment. The AMPUL Study Group. Am J Respir Crit Care Med 1999; 159: 1043-1051.

15 Bijl-Hofland ID, Cloosterman SG, Folgering HT, Akkermans RP, van Schayck CP. Relation of the perception of airway obstruction to the severity of asthma. Thorax 1999; 54: 15-19.

16 Koh YI, Choi IS, Lim H. Airway responsiveness as a direct factor contributing to the dyspnoea perception in asthma. Respir Med 2001; 95: 464-470.

17 Verberne AA, Frost C, Roorda RJ, van der Laag $\mathrm{H}$, Kerrebijn KF. One year treatment with salmeterol compared with beclomethasone in children with asthma. The Dutch Paediatric Asthma Study Group. Am J Respir Crit Care Med 1997; 156: 688-695.

18 Quanjer PH, Tammeling GJ, Cotes JE, Pedersen OF, Peslin R, Yernault JC. Lung volumes and forced ventilatory flows. Report working party standardisation of lung function tests, European Community for Steel and Coal. Official Statement of the European Respiratory Society. Eur Respir J 1993; 6: Suppl 16, 5-40.

19 Birnie D, thoe Schwartzenberg GW, Hop WC, van EssenZandvliet EE, Kerrebijn KF. Does the outcome of the tidal breathing and dosimeter methods of assessing bronchial responsiveness in children with asthma depend on age? Thorax 1990; 45: 199-202.

20 Pauwels RA, Löfdahl CG, Postma DS, et al. Effect of inhaled formoterol and budesonide on exacerbations of asthma. Formoterol and Corticosteroids Establishing Therapy (FACET) International Study Group. N Engl J Med 1997; 337: 1405-1411.

21 Payne DN, Rogers AV, Adelroth E, et al. Early thickening of the reticular basement membrane in children with difficult asthma. Am J Respir Crit Care Med 2003; 167: 78-82.

22 Woolcock AJ, Yan K, Salome CM. Effect of therapy on bronchial hyperresponsiveness in the long-term management of asthma. Clin Allergy 1988; 18: 165-176.

23 Sears MR, Greene JM, Willan AR, et al. A longitudinal, population-based, cohort study of childhood asthma followed to adulthood. N Engl J Med 2003; 349: 1414-1422.

24 Strunk RC, Weiss ST, Yates KP, et al. Mild to moderate asthma affects lung growth in children and adolescents. J Allergy Clin Immunol 2006; 118: 1040-1047.

25 de Marco R, Marcon A, Jarvis D, et al. Inhaled steroids are associated with reduced lung function decline in subjects with asthma with elevated total IgE. J Allergy Clin Immunol 2007; 119: 611-617.

26 Long-term effects of budesonide or nedocromil in children with asthma. The Childhood Asthma Management Program Research Group. N Engl J Med 2000; 343: 1054-1063. 
27 Pauwels RA, Pedersen S, Busse WW, et al. Early intervention with budesonide in mild persistent asthma: a randomised, double-blind trial. Lancet 2003; 361: 1071-1076.

28 Merkus PJ, van Pelt W, van Houwelingen JC, et al. Inhaled corticosteroids and growth of airway function in asthmatic children. Eur Respir J 2004; 23: 861-868.

29 Ward C, Pais M, Bish R, et al. Airway inflammation, basement membrane thickening and bronchial hyperresponsiveness in asthma. Thorax 2002; 57: 309-316.

30 Jeffery PK, Godfrey RW, Adelroth E, Nelson F, Rogers A, Johansson SA. Effects of treatment on airway inflammation and thickening of basement membrane reticular collagen in asthma. A quantitative light and electron microscopic study. Am Rev Respir Dis 1992; 145: 890-899.

31 Rasmussen F, Taylor DR, Flannery EM, et al. Risk factors for airway remodeling in asthma manifested by a low postbronchodilator FEV1/vital capacity ratio: a longitudinal population study from childhood to adulthood. Am J Respir Crit Care Med 2002; 165: 1480-1488.

32 Xuan W, Peat JK, Toelle BG, Marks GB, Berry G, Woolcock AJ. Lung function growth and its relation to airway hyperresponsiveness and recent wheeze. Results from a longitudinal population study. Am J Respir Crit Care Med 2000; 161: 1820-1824.

33 Le Souëf PN. Can measurements of airway responsiveness be standardized in children? Eur Respir J 1993; 6: 1085-1087.

34 Masoli M, Weatherall M, Holt S, Beasley R. Systematic review of the dose-response relation of inhaled fluticasone propionate. Arch Dis Child 2004; 89: 902-907.

35 Levine LS, Boston BA. Effect of inhaled corticosteroids on the hypothalamic-pituitary-adrenal axis and growth in children. J Pediatr 2000; 137: 450-454.

36 Brand PL. Inhaled corticosteroids reduce growth. Or do they? Eur Respir J 2001; 17: 287-294. 